\title{
ESTUDO DA SEDIMENTAÇÃO PARA O TRATAMENTO DE ÁGUA DE PROCESSO DE INDÚSTRIA BENEFICIADORA DE ARROZ
}

\author{
C. O. MEDEIROS ${ }^{1}$, R. R. LIMA ${ }^{1}$, R. A. MARTINS ${ }^{1}$, K. L. BUENO ${ }^{1}$, J. V. DIEL ${ }^{2}$, \\ L. M. RODRIGUES ${ }^{1}$, T. R. SOUZA ${ }^{1}$ \\ ${ }^{1}$ Universidade Federal do Pampa - UNIPAMPA, Engenharia Química, Campus Bagé \\ ${ }^{2}$ Universidade Federal do Pampa - UNIPAMPA, Engenharia de Produção, Campus Bagé \\ E-mail para contato: tania.souza@unipampa.edu.br
}

\begin{abstract}
RESUMO - Este trabalho é parte de um projeto de pesquisa realizado na UNIPAMPA, Campus Bagé, com a parceria entre os cursos de graduação de Engenharia Química, Engenharia de Produção e indústria de beneficiamento de arroz da Região da Campanha. O objetivo deste trabalho foi estudar o tratamento de água de processo de indústria de beneficiamento de arroz, enfatizando a análise das etapas de sedimentação (batelada e contínua). A sedimentação é uma operação unitária, presente nas estações de tratamento de água - ETA, baseada na diferença de densidades entre a água e os sólidos em suspensão, acarretando na deposição e posterior remoção desses sólidos. Com a etapa de sedimentação em batelada determinou-se a melhor condição de operação, onde houve a obtenção de uma maior quantidade de flocos seguida de decantação eficiente. Esses dados foram aplicados no módulo de sedimentação contínua, obtendo a vazão do lodo espessado e o valor de vazão de clarificado.
\end{abstract}

\section{INTRODUÇÃO}

O tratamento de água industrial é um processo de adequação da água bruta, geralmente proveniente de rios, lagos ou barragens, às condições necessárias ao processo. Esse tratamento garante que os valores dos parâmetros biológicos, físicos e químicos não ultrapassem valores estipulados pela legislação vigente. Nesse caso, em indústrias alimentícias faz-se necessário à obtenção de água de processo que atendam os limites estabelecidos para água potável, pois será utilizada em contato direto com o arroz.

Segundo Richter e Netto (2000), água potável é uma água própria para o consumo humano, cujos parâmetros microbiológicos físicos, químicos e radioativos atendam os padrões de potabilidade e que não ofereça riscos à saúde. Esses padrões de potabilidade podem ser determinados pela Portaria 2914/2011 do Ministério da Saúde.

A água utilizada no processo de parboilização do arroz é proveniente de uma barragem, que se localiza dentro da empresa, e precisa passar por um tratamento para se tornar potável e livre de 


\section{9 a 22 de outubro de 2014 \\ Florianópolis/SC}

qualquer contaminante que possa interferir no alimento. Para tanto, a empresa contém uma Estação de Tratamento de Efluentes (ETA) que realiza as etapas de: gradeamento, coagulação, floculação, decantação e filtração.

O processo de Tratamento de água inicia-se pelo gradeamento, onde a água da barragem é captada por bombas de sucção e seguem para um sistema de grades que impede a entrada de elementos macroscópicos grosseiros (animais mortos, folhas, etc.) (BRAGA, 2005).

Após o gradeamento, a água segue por uma tubulação onde é adicionada uma quantidade de floculante, pré-estabelecida por testes laboratoriais realizados em Jar-test. O floculante normalmente utilizado é o sulfato de alumínio. Essa etapa, conhecida como coagulação, visa à formação de flocos que serão aderidos a partículas de impurezas presentes na água (BRAGA, 2005).

O processo de floculação é um promotor ou auxiliar da sedimentação, trata-se de precipitação de soluções coloidais, sob a forma de flocos tênues, causada por reagentes químicos (floculante e auxiliar de floculante). O floculante mais utilizado em uma Estação de Tratamento de Água (ETA) é o sulfato de alumínio. Com o aumento do diâmetro das partículas há, consequentemente, o aumento de sua velocidade de sedimentação ao longo da altura do decantador (GEANKOPLIS, 1998).

O processo de decantação, também conhecido como sedimentação, é utilizado para remoção de partículas sólidas em suspensão, sendo um dos mais comuns no tratamento da água. Consiste na utilização das forças gravitacionais para separar partículas de densidade superior a da água, depositando-as em uma superfície ou zona de armazenamento. As partículas que não são removidas na sedimentação, seja por seu pequeno tamanho ou por serem de densidade muito próxima a da água, deverão ser removidas na filtração. A etapa de sedimentação para o tratamento de águas pode ocorrer de forma contínua ou descontínua, em equipamentos chamados decantadores ou sedimentadores (CREMASCO, 2012).

A sedimentação natural ocorre quando a concentração volumétrica das partículas é maior que 40\%. A sedimentação industrial ocorre nos equipamentos tanques de decantação ou decantadores, que podem atuar como espessadores ou clarificadores. Quando o produto é o lodo, se trata de espessador e quando o produto é o líquido límpido, tem-se um clarificador (FOUST et al., 1982).

Os decantadores geralmente apresentam operação contínua e apresentam uma parte cilíndrica e outra parte cônica, o que facilita a retirada da corrente de fundo (ou lodo). A parte superior do decantador apresenta a saída da água tratada por transbordamento, resultando no clarificado. A alimentação do decantador, com a água a tratar (água bruta) é realizada na parte central do equipamento. (NUNES, 2008 e Di BERNARDO e DANTAS, 2005).

Para a determinação da vazão de sedimentação foi utilizado o método de Kynch, aplicado na etapa de sedimentação em batelada, para que assim pudessem ser estimados os volumes ideais a serem utilizados na etapa de sedimentação contínua (CREMASCO, 2012).

A partir da Equação 1, foi calculada a vazão de sedimentação: 


$$
A=\frac{Q_{a} \varepsilon_{p a}}{q_{i}} \cdot\left(\frac{1}{\varepsilon_{p i}}-\frac{1}{\varepsilon_{p l}}\right)
$$

onde $A$ é a área do sedimentador, $Q_{a}$ é a vazão de sedimentação, $q_{i}$ é a velocidade de sedimentação, $\varepsilon_{p a}, \varepsilon_{p i}$ e $\varepsilon_{p l}$ são as concentrações de alimentação, de clarificado e de lodo, respectivamente.

Com o uso do módulo de sedimentação contínua obtêm-se o valor de vazão de lodo espessado, na saída inferior do decantador. A partir desse valor determina-se a vazão de clarificado com o uso da Equação 2.

$$
Q_{e}=Q_{a} \varepsilon_{p a} \cdot\left(\frac{1}{\varepsilon_{p i}}-\frac{1}{\varepsilon_{p l}}\right)
$$

onde $Q_{e}$ é a vazão do clarificado.

Este trabalho é parte integrante de um projeto maior de reestruturação da ETA presente na indústria de beneficiamento de arroz e tem por objetivo analisar a etapa da sedimentação que ocorre no decantador, verificando em laboratório (escala batelada e contínua) a necessidade de ampliar a quantidade de produtos (floculante e polímeros) utilizados pela empresa ou ainda a necessidade de melhorias físicas no decantador da empresa.

\section{METODOLOGIA}

A amostra de água bruta a tratar foi coletada em barragem da região do Pampa Gaúcho, fonte de abastecimento da indústria de beneficiamento de arroz.

Foi utilizada uma estação de tratamento de águas em escala laboratorial (Figura 1) para o estudo do processo de sedimentação, em batelada e contínua. Os parâmetros avaliados foram vazão de sedimentação, determinada pelo processo em batelada, vazão de alimentação da água bruta e de reagentes químicos, e a eficiência da sedimentação, determinados pelo processo contínuo.

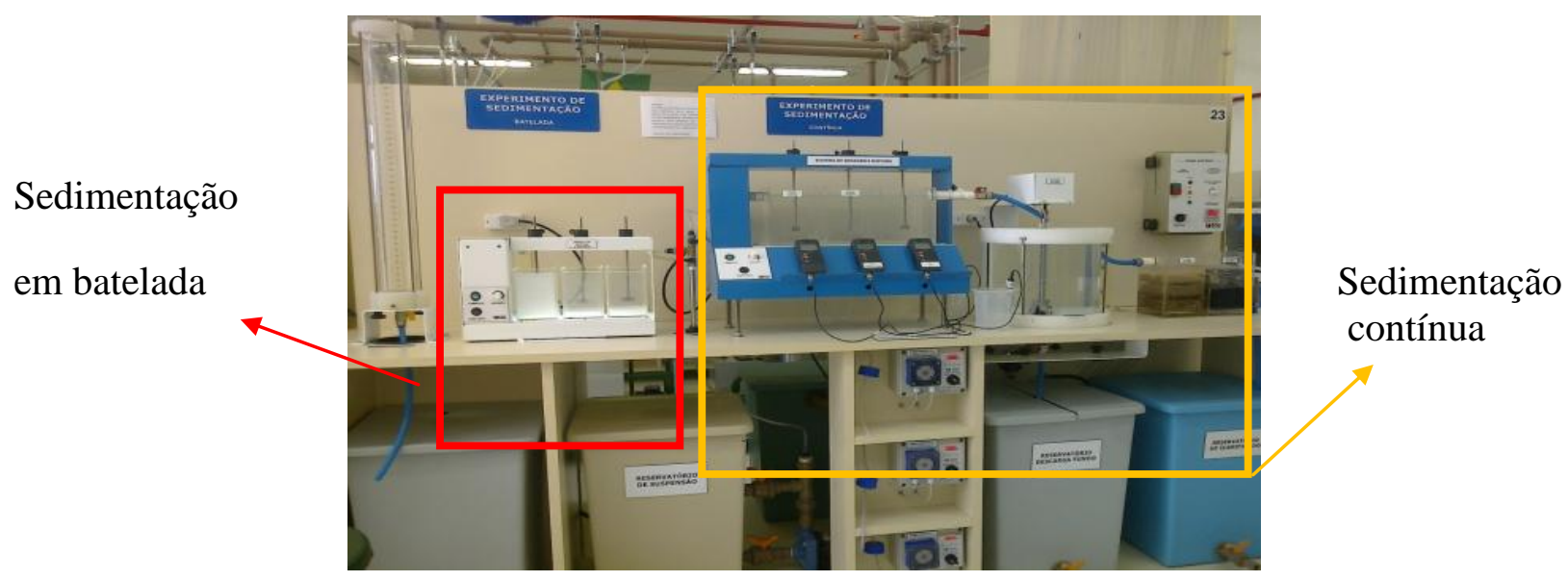


Figura 1 - Estação de tratamento de águas em escala laboratorial.

Os reagentes químicos empregados foram para o ajuste de $\mathrm{pH}$ da água bruta um alcalinizante, floculante e auxiliar de floculante (resina polimérica), todos produtos utilizados na ETA da empresa, para a promoção do processo de sedimentação de impurezas presentes na água bruta de barragem.

Para a determinação da vazão de sedimentação foi utilizado o método de Kynch, aplicado na etapa de sedimentação em batelada, para que assim pudessem ser estimados os volumes ideais a serem utilizados na etapa de sedimentação contínua. A partir da Equação 1, foi calculada a vazão de sedimentação.

Com o uso do módulo de sedimentação contínua obtêm-se o valor de vazão de lodo espessado, na saída inferior do decantador. A partir desse valor determina-se a vazão de clarificado com o uso da Equação 2.

\section{RESULTADOS E DISCUSSÕES}

Realizaram-se alguns experimentos de sedimentação em batelada com o objetivo de obter a quantidade necessária de alcalinizante, floculante e auxiliar de floculação que garanta a obtenção da sedimentação de partículas, otimizando a aplicação desses produtos. A partir desses dados determinou-se a velocidade de sedimentação para ser aplicada no módulo de sedimentação contínuo.

A Figura 2 mostra experimento realizado em Jar-test, onde verifica-se o comportamento de amostras de um litro de água bruta com aplicação de diferentes concentrações dos produtos.

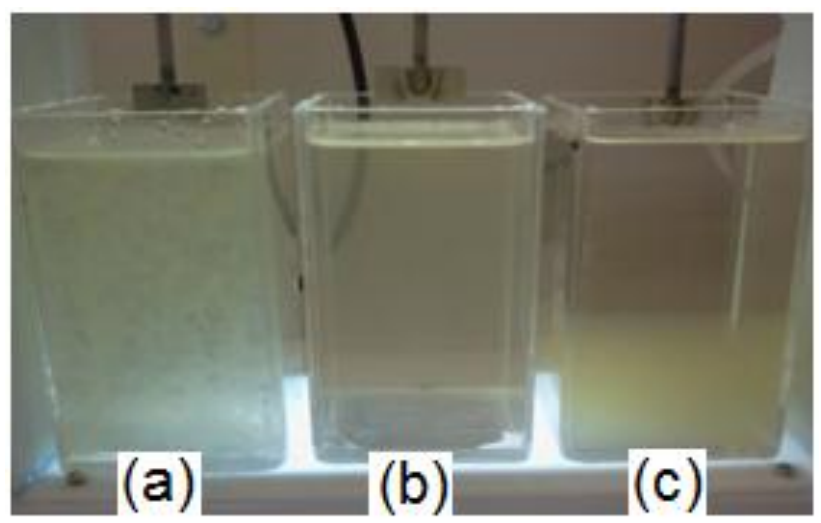

Figura 2 - Curva de Sedimentação em Batelada.

Em 2 (a) verifica-se que houve formação de flocos, entretanto não houve sedimentação. Em 2 (b) nota-se uma menor quantidade de flocos que sedimentaram. Mas, a melhor condição mostrada na Figura 2, está em 2 (c), onde há a formação de uma maior quantidade de flocos que sedimentaram. 
Para obter a melhor condição de operação, Figura 2 (c), a quantidade necessária de alcalinizante foi de $5,0.10^{-1} \mathrm{ml}$ de solução com concentração de $1,0.10^{-3} \mathrm{~g} / \mathrm{L}$, a vazão de floculante foi de $1 \mathrm{ml}$ de solução com concentração de $1,0 \cdot 10^{-2} \mathrm{~g} / \mathrm{L}$ e de polímero foi de $3 \mathrm{ml}$ de solução com concentração de $1,0.10^{-2} \mathrm{~g} / \mathrm{L}$.

Os dados obtidos no Jar-test foram aplicados na etapa de sedimentação em batelada para determinar a velocidade de decantação. A Figura 3 mostra os dados obtidos nesta etapa.

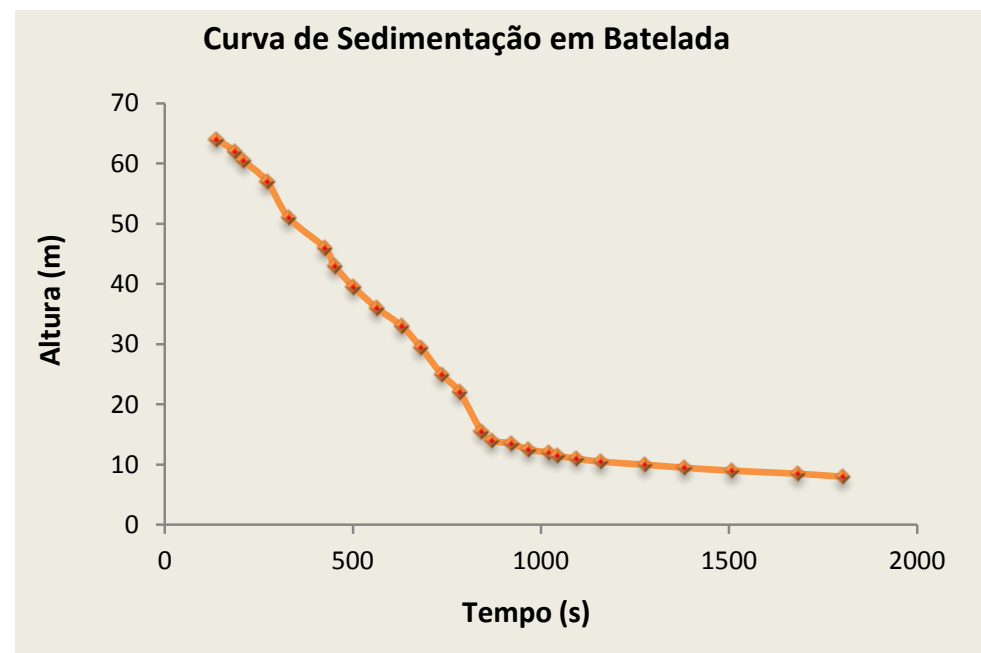

Figura 3 - Curva de Sedimentação em Batelada.

Com base nos dados da Figura 3 e com a Equação 1 calculou-se a vazão necessária ao módulo de sedimentação contínua, obtendo o valor de $0,3 \mathrm{~L} / \mathrm{min}$ de água bruta. Aplicando-se esse valor no módulo obteve-se a vazão do lodo espessado $\left(Q_{l}\right)$ de $0,0205 \mathrm{~L} / \mathrm{min}$, mantendo os valores de vazão de solução alcalina $\left(Q_{a l c}\right)$ de $6,5 \cdot 10^{-4} \mathrm{~L} / \mathrm{min}$, vazão de floculante $\left(Q_{f l o c}\right)$ de $3.10^{-4} \mathrm{~L} / \mathrm{min}$ e a vazão de polímero $\left(Q_{p o l}\right) 3.10^{-4} \mathrm{~L} / \mathrm{min}$, pré determinados no módulo de sedimentação em batelada.

Utilizando a Equação 2 determina-se a vazão de clarificado $\left(Q_{e}\right)$ cujo valor é 7,567 $10^{-2} \mathrm{~L} / \mathrm{min}$.

\section{CONSIDERAÇÕES FINAIS}

Com a etapa de sedimentação em batelada determinou-se a melhor condição de operação, onde houve a obtenção de uma maior quantidade de flocos seguida de decantação eficiente. Para obter essa condição, para cada litro de água bruta, são necessários: $5,0.10^{-1} \mathrm{ml}$ de alcalinizante com concentração de $1,0.10^{-3} \mathrm{~g} / \mathrm{L}, 1 \mathrm{ml}$ de floculante com concentração de $1,0.10^{-2} \mathrm{~g} / \mathrm{L}$ e $3 \mathrm{ml}$ de polímero com concentração de $1,0.10^{-2} \mathrm{~g} / \mathrm{L}$. 
Esses dados foram aplicados no módulo de sedimentação contínua, obtendo a vazão do lodo espessado $\left(Q_{l}\right)$ de $0,0205 \mathrm{~L} / \mathrm{min}$. Pode-se então, calcular o valor de vazão de clarificado $\left(Q_{e}\right)$ cujo valor é $7,56710^{-2} \mathrm{~L} / \mathrm{min}$.

A atuação do grupo de trabalho promoverá a reavaliação do decantador, que compõe a estação de tratamento de água da referida empresa, propondo melhorias e enfatizando a necessidade da existência de um tanque pulmão para reservar a água tratada, após a filtração. Espera-se com essas melhorias obter uma melhor qualidade da água de processo industrial, atendendo a Legislação vigente.

\section{Agradecimentos}

À UNIPAMPA pela infraestrutura e profissionais disponibilizados para a execução da pesquisa, e à indústria de beneficiamento de arroz da região do RS pela parceria na pesquisa.

\section{REFERÊNCIAS}

BRAGA, B.; HESPANHOL, I.; CONEJO, J. G. L., et al. Introdução à Engenharia Ambiental, 2a Edição, Ed. Pearson Prentice Hall, São Paulo. 2005, 336 p.

CREMASCO, M. A. Operações Unitárias em Sistemas Particulados e Fluidodinâmicos. São Paulo: Ed. Blucher, 2012.

FOUST, A. S et al. Princípios das Operações Unitárias. São Paulo: Ed. LTC, 1982.

GEANKOPLIS, C. J. Procesos de Transporte y Operaciones Unitarias. México: CECSA, 1998.

Di BERNARDO, L.; DANTAS, A. D. B. Métodos e Técnicas de Tratamento de Água. $2^{\mathrm{a}}$ ed. Associação Brasileira de Engenharia Sanitária e Ambiental, 2005. 2v.

NUNES, F. J. - Estudo da sedimentação gravitacional de suspensão floculante - Dissertação de sedimentação de Pós-Graduação em Engenharia Química - Uberlândia/MG, 2008.

RICHTER, C. A.; NETTO, J. M. de A. Tratamento de Água - Tecnologia Atualizada. $3^{\mathrm{a}}$ ed. São Paulo: Ed. Blucher, 2000, 332 p. 